\title{
Correction to "A Role for the Orphan Human Cytochrome P450 2S1 in Polyunsaturated Fatty Acid $\omega-1$ Hydroxylation Using an Untargeted Metabolomic Approach"
}

\begin{abstract}
In the above article [Fekry MI, Xiao Y, Berg JZ, and Guengerich FP (2019) Drug Metab and Dispos November 2019, 47 (11) 1325-1332; DOI: https://doi.org/10.1124/dmd.119.089086 ], in Figure 4D the $\mathrm{m} / \mathrm{z}$ peak labeled "275.2019" should be changed to "273.1863". The mistake was found to be due to mislabeling by a mass spectrometry software error that was not caught by the authors at the proof stage. This change does not change the interpretation of the results. The corrected figure 4 is displayed below and in the PDF and HTML versions of this article.
\end{abstract}

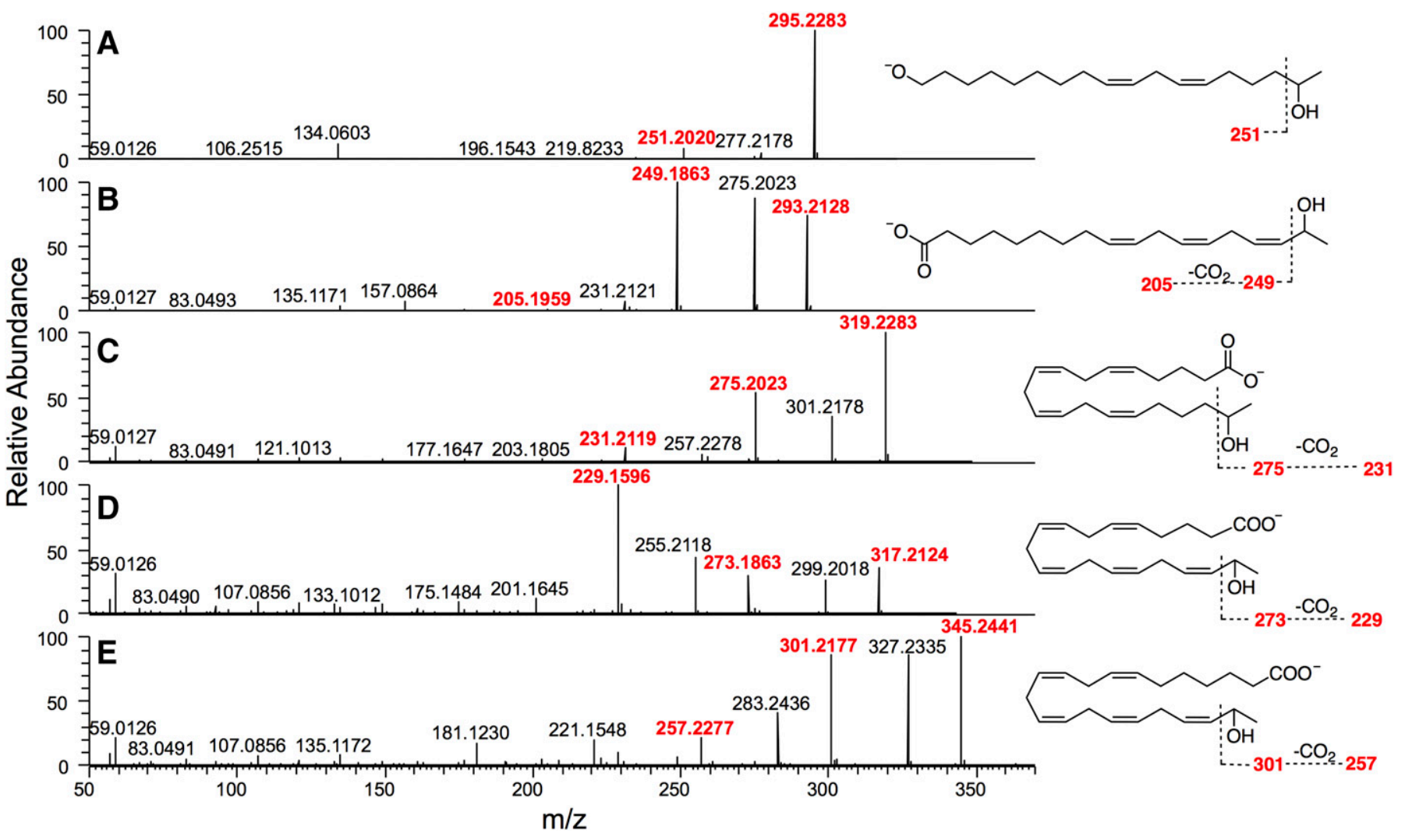

The authors apologize for any inconvenience caused by these errors. 